\title{
$\underline{\text { Raised blood pressure and risk of dementia }}$
}

Dr. John Gregson $\mathrm{PhD}^{1}$, Dr. Nawab Qizilbash $\mathrm{MD}^{1,2}$, Professor Stuart Pocock $\mathrm{PhD}^{1}$

${ }^{1}$ Department of Medical Statistics, London School of Hygiene \& Tropical Medicine ${ }^{2} \mathrm{OXON}$ Epidemiology

Corresponding author:

Professor Stuart Pocock

Professor of Medical Statistics

Department of Medical Statistics

London School of Hygiene \& Tropical Medicine

Keppel Street

London

WC1E7HT

stuart.pococks@1shtm.ac.uk 
Abell and colleagues ${ }^{1}$ reported that elevated systolic blood pressure (SBP) at age 50 , even below the conventional threshold for treating hypertension, was associated with increased risk of dementia. This association was not present for diastolic blood pressure (DBP), nor for SBP later in life, and requires cautious interpretation and exploration in other studies.

Accordingly, we analysed data from 730492 people in the Clinical Practice Research Datalink (CPRD). We included patients with a blood pressure measurement aged 45-75 after 1992. To achieve comparability with Abell's analysis reported from the Whitehall study and to minimize bias caused by reverse causation, we excluded the period within 10 years of blood pressure measurement. Analyses were according to age at first blood pressure measurement: 45-54 years $(\mathrm{N}=317349$, of whom 1149 developed dementia), 55-64 years $(\mathrm{N}=248943,5499$ dementia), 65-74 years $(\mathrm{N}=164200,10109$ dementia). Mean age at diagnosis of dementia was 79.8 years. We used Poisson regression models adjusting for gender and age-at-risk; although adjustment for several additional factors did not alter our findings.

Like Abell, we did not find a positive association of SBP with dementia in the two older age groups at blood pressure measurement (data not shown). We therefore focussed attention on people aged 45-55 years at blood pressure measurement. Amongst this group, we found a weak association of SBP with risk of dementia: risk ratio for $\mathrm{SBP} \geq 140 \mathrm{mmHg} 1.12$ (95\% CI, 1.00-1.26). We found no clear threshold for this positive association of SBP with dementia risk (Figure 1). In contrast to Abell, we also found a similar weak association between DBP and risk of dementia: risk ratio for DBP $\geq 90 \mathrm{mmHg} 1.15$ (95\% CI, 1.02-1.30). Finally, we found that these associations depended on the dementia subtype: SBP was associated with vascular dementia (RR for SBP $\geq 140 \mathrm{mmHg}$ : $1.52,95 \%$ CI 1.18-1.96), but not with Alzheimer's disease (RR for SBP $\geq 140 \mathrm{mmHg}$ : 0.99, 95\% CI 0.86-1.14). This lack of a positive association between blood pressure and risk of Alzheimer's disease is consistent with previous genetic studies ${ }^{2}$ and meta-analyses. ${ }^{3}$

Thus our findings do not support the claim by Abell and colleagues that SBP at age 50 below the conventional $\geq 140 \mathrm{mmHg}$ for hypertension is associated with an increased risk of dementia. We do 
find that both systolic and diastolic hypertension at age 50 are associated with an increased risk of vascular dementia ( $21 \%$ of all dementia cases), but not Alzheimer's disease.

1. Abell JG,Kivima M,Dugravot A,Tabak AG,Fayosse A,Shipley M. Association between systolic blood pressure and dementia in the Whitehall II cohort study: role of age, duration, and threshold used to define hypertension. Eur Heart J 2018;39:3119-3125.

2. Østergaard SD,Mukherjee S,Sharp SJ,Proitsi P,Lotta LA,Day F,Perry JRB,Boehme KL,Walter S,Kauwe JS,Gibbons LE, Alzheimer's Disease Genetics Consortium, The GERAD1 Consortium, EPIC-Interact Consortuim, Larson EB,Powell JF,Langenberg C,Crane PK,Wareham NJ,Scott RA. Associations between Potentially Modifiable Risk Factors and Alzheimer Disease:A Mendelian Randomization Study. PLoS Med 2015;12:e1001841; discussion e1001841.

3. Power MC,Weuve J,Gagne JJ,McQueen MB,Viswanathan A,Blacker D. The association between blood pressure and incident Alzheimer disease: a systematic review and meta-analysis. Epidemiology 2011;22:646-659.

\section{Acknowledgements}

We thank Drs Ian Douglas, Masao Iwagami and Michelle Johnson for their help with data acquisition and analysis. WE thank Professor Neil Pearce for help with study oversight.

\section{Funding}

This work was funded by a grant from Alzheimer's Society, UK 
Figure 1: Risk of all dementia, Alzheimer's disease and vascular dementia according to systolic and diastolic blood pressure at age 45-54 years
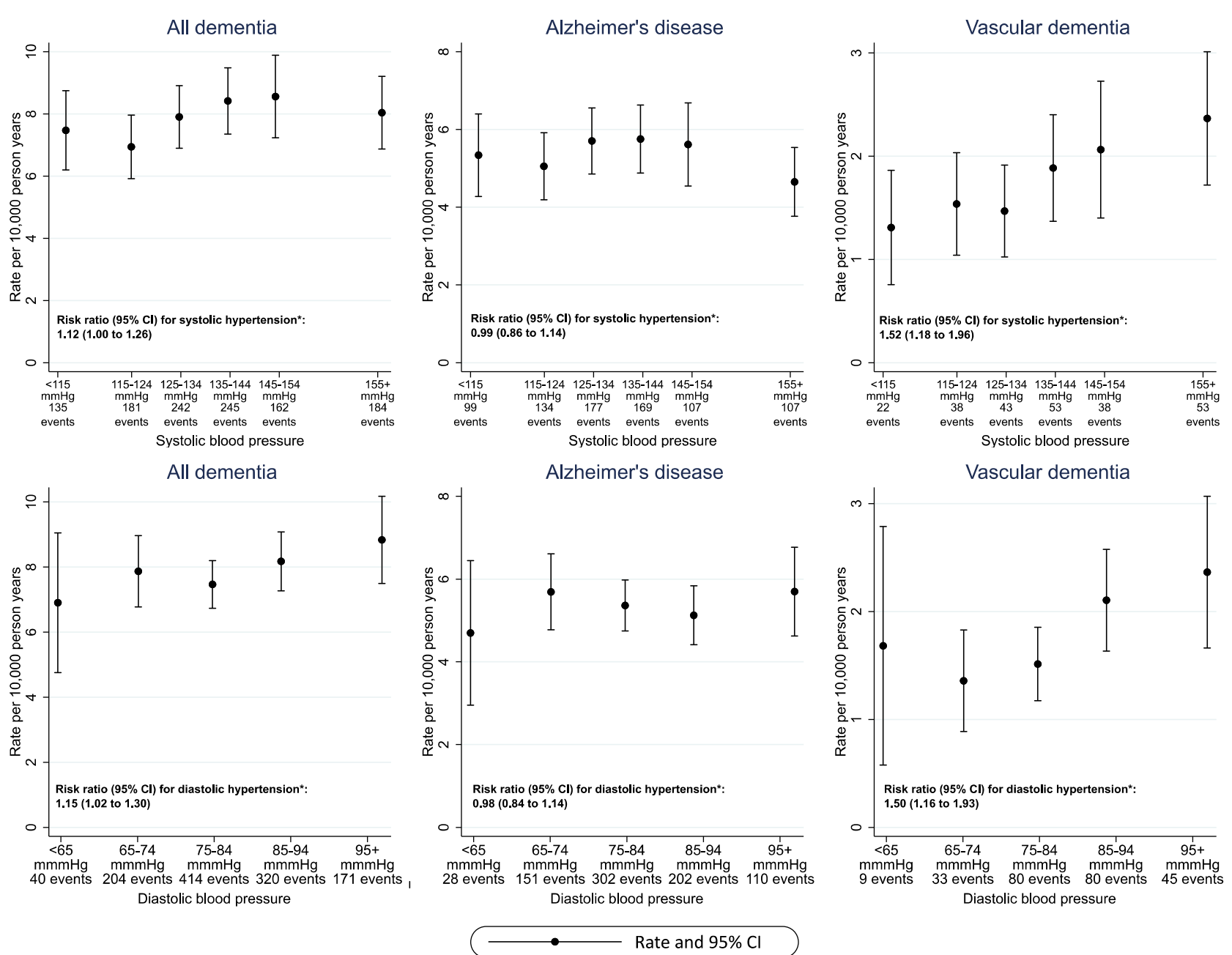

*We define systolic hypertension as $\geq 140 \mathrm{mmHg}$ and diastolic hypertension as $\geq 90 \mathrm{mmHg}$ 
